\title{
How Transboundary Learning Occurs: Case Study of the ASEAN Smart Cities Network (ASCN)
}

\author{
Si-Ying Tan ${ }^{1}$, Araz Taeihagh ${ }^{2, * \mathbb{D}}$ and Kritika Sha ${ }^{2} \mathbb{D}$ \\ 1 Leadership Institute for Global Health Transformation (LIGHT), Saw Swee Hock School of Public Health, \\ National University of Singapore, Singapore 117549, Singapore; s.tan14@u.nus.edu \\ 2 Lee Kuan Yew School of Public Policy, National University of Singapore, Singapore 259771, Singapore; \\ kritika.sha@u.nus.edu \\ * Correspondence: spparaz@nus.edu.sg or araz.taeihagh@new.oxon.org; Tel.: +65-6601-5254
}

Citation: Tan, S.-Y.; Taeihagh, A.; Sha, K. How Transboundary Learning Occurs: Case Study of the ASEAN Smart Cities Network (ASCN). Sustainability 2021, 13, 6502. https://doi.org/10.3390/su13116502

Academic Editor: Wann-Ming Wey

Received: 26 April 2021

Accepted: 1 June 2021

Published: 7 June 2021

Publisher's Note: MDPI stays neutral with regard to jurisdictional claims in published maps and institutional affiliations.

Copyright: (c) 2021 by the authors. Licensee MDPI, Basel, Switzerland. This article is an open access article distributed under the terms and conditions of the Creative Commons Attribution (CC BY) license (https:// creativecommons.org/licenses/by/ $4.0 /)$.

\begin{abstract}
While policy study of smart city developments is gaining traction, it falls short of understanding and explaining knowledge transfers across national borders and cities. This article investigates how transboundary learning occurs through the initiation and development of a regional smart cities network: the ASEAN Smart Cities Network (ASCN). The article conducts an in-depth case study from data collected through key informant interviews and document analysis. Spearheaded by Singapore in 2017, ASCN is seen as a soft power extension for Singapore, a branding tool for ASEAN, and a symbiotic platform between the private sector and governments in the region. Most transboundary knowledge transfers within the ASCN are voluntary transfers of policy ideas. Effective branding, demand for knowledge, availability of alternative funding options, enthusiasm from the private actors, and heightened interest from other major economies are highlighted as facilitators of knowledge transfer. However, the complexity of governance structures, lack of political will and resources, limited policy capacity, and lack of explicit operational and regulatory mechanisms hinder transboundary learning. The article concludes that transboundary learning should go beyond exchanges of ideas and recommends promoting facilitators of knowledge transfer, building local policy capacity, encouraging collaborative policy transfer, and transiting from an information-sharing platform to tool/instrument-based transfer.
\end{abstract}

Keywords: smart city; policy transfer; transboundary learning; ASEAN; ASCN; enablers; barriers; motivations

\section{Introduction}

Policy transfer is an applied framework that is useful in understanding the dimensions of policy change, which includes understanding the processes, agents, and constraints of transfer [1,2]. While understanding these dimensions of policy transfer is important, the conceptual literature on policy transfer has emphasised that attention should be given to politics in the transfer process. For example, policy transfer has been described as a highly politicised process to justify an existing policy position, creating what is known as 'nonlessons' or 'negative lessons' [3]. Correspondingly, policy transfer is coined as a 'contested process' which is highly influenced by bureaucratic politics from the receiving or importing countries [4]. Learning from abroad can also be an 'innately political undertaking' in which actors strategically access, evaluate, and disseminate information in the policymaking process as a means to enhance their argumentative power and draw selective lessons in advocating a policy [5].

Different contexts of transfer have been identified in the literature. Most of these are related to the conceptual application of policy transfer to explain the policy learning processes taking place within the government. These include within-country transfer (from one jurisdiction to another within the same country), transboundary transfer from one country to another [1,4,6-14], and transfer between international organisations [15]. 
Literature on international and transboundary policy transfer typically encapsulates both technical knowledge transfer and a soft power extension. These transfers tend to flow from an advanced country to a developing country or from a well-developed jurisdiction to a less-developed jurisdiction within the same country [7]. The South Korean initiative in Honduras (construction of Honduras economic zones), the Sino-Singapore Suzhou Industrial Park, which is a collaborative developmental initiative between the Singapore and Suzhou government in China [8], the City Mentorship Programmes among different cities in Africa [9], and the transfer of Delta planning expertise from the Netherlands to Bangladesh to help Bangladesh solve its recurring water management problems [10] are some of the key examples of transboundary transfer that signal both diplomatic intentions and economic interests of the transferring country to the recipient country, typically established through technical and operational knowledge transfer.

Nevertheless, an international and transboundary transfer can occur between or among advanced countries/jurisdictions through broad adoption of ideas, concepts, and philosophies modified to suit the local contexts. For instance, the transfer of integrated care policies for long-term care from Europe to Singapore is perceived to occur in a multiscalar and multi-site network that involves the transfer of ideas, philosophies, concepts, and integrated care principles from multiple advanced jurisdictions in Europe to Singapore [11]. In the same vein, there can be city-to-city policy transfer between countries, which draws policy ideas from foreign jurisdictions and less of policy goals and content, policy instruments, and negative lessons [12]. Likewise, the transfer of the cap-and-trade policy to Tokyo [13] and Japan's adoption of feed-in-tariff through a structured eight-step process [14] reflect a broad-based policy transfer process that draws inspirations and ideas from multiple advanced jurisdictions through a fact-finding approach that dispatches official delegations to learn from abroad. Furthermore, a cross-country collaborative transfer between Australia and Sweden on a regulatory compliance programme has shown that transboundary transfer is an iterative process linked to domestic policy cycles and tends to be effective when mobilised around similar policy concerns from both jurisdictions [6].

While much has been written about Singapore's involvement in transnational urban development such as the Sino-Singapore Tianjin Eco-city [16-19] and Suzhou's industrial park $[8,18,19]$, more research is needed for explaining the process of knowledge transfer in these urban development initiatives, the explicit roles and expertise of the agents involved in the transfer, and the extent to which these transfers facilitate transboundary learning. There remain knowledge gaps in understanding how transfer occurs in the context of smart city developments and transboundary learning in a regional network such as ASEAN that presents diversity in developmental stages, cultural norms, and economic interests for each country. Paving the way to a common vision for the region by confronting these diversities is a key challenge to any regional initiative.

Using a case of the initiation and development of ASEAN Smart Cities Network (ASCN), a regional smart city network in Southeast Asia, we examined the early policy processes of ASCN spearheaded by Singapore since November 2017 during the ASEAN summit by focusing on the agenda-setting and formulation processes. Specifically, this study aims to find out how a regional smart city development network evolves in one of the most culturally diverse regions in the world, how policy ideas and initiatives are transferred across national borders, how local conditions come into play in the transfer processes, and how a common agenda is pursued and policy challenges are addressed by various agents. To achieve these aims, we asked the following research questions: (i) As a global city and a forerunner in smart city developments, how does Singapore facilitate knowledge exchange and transfer within the ASCN? (ii) What is the significance of ASCN to Singapore and ASEAN? (iii) Who are the agents involved in the transfer processes, and what are the resources and expertise they offer to ASCN? (iv) What are the scopes and dimensions of knowledge exchange and policy transfer in ASCN, and how do these transfers occur? (v) What are the enablers for and barriers to these transfers? 
The remainder of this paper is organised as follows: the next section provides a background to the literature of policy transfer. The third section reports the case study method undertaken in the inquiry of this research and details the processes of data collection and data analysis. The fourth section documents the case by describing the formation of the ASCN, as well as analysing the major actors of the ASCN, the roles that Singapore as an inaugural host plays in the formation of this network, the significance of the ASCN, scopes of knowledge transfer and exchange in ASCN, and facilitators of and barriers to transboundary learning and knowledge exchange in the ASCN. The fifth section discusses the nature of transfer within members in the ASCN, and how and from where the network could potentially derive lessons and inspirations, as well as the importance of consideration of local contexts. Section 5 provides policy recommendations, and the final section concludes with key insights for other regional smart cities networks worldwide.

\section{Background to Policy Transfer}

\subsection{Policy Transfer: Definitions and Conceptual Evolution}

There have been several mechanisms for categorising the various overlapping concepts of policy transfer, convergence, and diffusion, with policy transfer and diffusion categorised under policy learning [20], convergence seen as a form of transfer driven by structural forces [21], and policy transfer seen as an overarching concept over diffusion [22]. Here, we focus on understanding the role of policy transfer and diffusion, particularly in terms of transboundary learning.

Policy transfer is broadly defined as a process through which 'knowledge about policies, administrative arrangement institutions, and ideas in one political setting is used in development of policies, administrative arrangement institutions, and ideas in another political setting' [23]. In its earlier days, policy transfer literature focused on understanding the role of agency [21], the logic behind the selection of ideas, lessons learnt from other systems [24], and structural forces leading to convergence of policies [25]. Increasingly, there has been a greater emphasis placed on understanding the role of agents (individuals, interest groups, and organisations) in disseminating policies. It has moved away from viewing transfer as just 'lesson-drawing', which dealt with a voluntary form of policy transfer emerging from a desire to adopt best practices, to including a more coercive form, where one government can push another to adopt a certain policy [23]. The move towards understanding an agents' motivations and strategies in policy transfer also puts emphasis on "the force of knowledge and the agency" [26], while still including the impact of various structural forces [21]. Therefore, exploring policy transfer allows us to observe the variation in policy goals and objectives, but still accounts for any possible differences in the type of policy tools or instruments selected. Likewise, policy diffusion can be defined as the processes through which policy choices in one country either liberate or restrict the policy choices in another country [27]. Initial explorations of policy diffusion were in the form of policy innovation, with its impetus emerging from outside the polity due to the expanse of innovation across different governments or sectors within the government [28]. Understanding the mechanisms of policy transfer and diffusion such as learning from early adopters, competition between cities, imitation of larger organisations, and coercion through vertical or horizontal sectors can help us identify the different patterns of movement of policy innovation across cities [29]. Alternatively, other mechanisms that target transboundary diffusion of economic policy include (1) altered payoffs where the policy selections and decisions made in one country affect the financial, material, and reputational benefits for other countries; and (2) selection of policies in one country altering the information set that determines policy choices of other countries [27]. This approach emphasises that governments systematically consider the choices made by culturally similar countries while shaping their own choices.

Although both diffusion and transfer in policy studies contribute to policy change, diffusion focuses on the structure, whereas policy transfer focuses more on agency [30]. They also play a key role in understanding the mechanisms of policy change, policy adoption, 
and movement across transboundary scales. As we want to understand the mechanisms behind transboundary policy learning, we focused our research under policy transfer and diffusion that occurs intentionally. Moreover, as both conceptualisations can manifest distinctly, we aimed to integrate them to establish a pattern for understanding transboundary learning, as elaborated below. Our approach, based on an existing framework for understanding policy transfer [31], asks the following questions: Why does the policy transfer process occur at transboundary level? Who are the agents involved in this process? What forms does policy transfer at this scale take and what facilitates it? Lastly, what are the enablers and barriers to policy transfer?

\subsection{Why Transfer}

From a transferring country's perspective, transboundary policy transfer occurs as countries seek to build legitimate identities in pursuing their geopolitical interests in the region. From a macroeconomic perspective, transboundary transfer of technical knowledge in city-building is a strategic means for a developed foreign state to improve its commercial interests in a developing country [18,32]. For instance, in Singapore's transboundary initiatives with China through the Suzhou Industrial Park and eco-city in Tianjin through the Sino-Singapore Tianjin Eco-city project, Singapore adopted a 'self-learning through teaching' approach. This approach entails knowledge transfer through a mutually reinforcing and concurrent transfer process that involved direct teaching and self-learning which occurred via feedback from receiving cities (Suzhou and Tianjin) [18]. In the same vein, the intention of policy transfer for the European Commission in Latin America was driven by the motivation of EU members to increase their sphere of influence while capitalising on the rapid economic growth in emerging economies such as Brazil and its political position as a regional leader in South America [32].

On the other hand, receiving countries of policy transfer from a developed foreign state is an effective way for the former to strengthen its governance and policy capacities. In particular, Brazil's borrowing and learning of EU Cohesion Policy was pursued as a means to strengthen its regional policy and reduce territorial developmental disparities. Drawing practical insights from the EU Cohesion Policy, Brazil embarked on a policy learning journey from the selection of geographical targets for development, attraction of dedicated investments, implementation of programmes, and the practical management of tools, as well as the specific design and delivery of policies [32].

\subsection{Agents of Policy Transfer}

In the literature, three groups of agents have been identified to play instrumental roles in transnational or transboundary policy transfer. The first group of agents includes transnational private and corporate actors such as specialist consultancies with expertise in urban planning and design as policy transfer agents [33]. They work closely with stateowned conglomerates with core competencies in transportation, waste management, and property construction in the Sino-Singapore Tianjin Eco-city project [33]. The literature also highlighted the crucial role of local technocrats such as engineers and consultants in ensuring that the process of knowledge transfer is rooted before the foreign experts depart from the country [33].

Local-level bureaucrats and technocrats who possess exhaustive and extensive local networks, and who can navigate the local policy environment to see through the implementation of ideas constitute the second group of agents that are important to facilitate transboundary learning and transfer. For example, municipal leaders who steer the local adoption of transferred policy ideas and local officials who learn and shape their respective organisational roles to align with the overarching transfer goals are crucial in urban climate policy transfer [12,13]. In the adoption of the cap-and-trade policy in Tokyo, the political commitment of the Governor of Tokyo was instrumental in enabling the climate change mitigation policies to be formally established in the policy agenda [13]. However, to achieve scalability and sustainability, municipal officials play important roles as learning agents 
when localising these policies [6,12]. In the transfer of urban spatial policies, they learn and adapt these policies to their respective contexts and tap into their local networks for political opportunities and their interpersonal relations with their foreign peers for mutual learning [12]. These local actors often have access to broad local networks that are crucial in translating the policy initiatives on the ground [6].

Lastly, think tanks and academics represent the third important group of agents of policy transfer, especially in promoting knowledge diffusion from foreign countries to the local bureaucrats [13,21]. In Tokyo, the academics and nongovernmental organisations play important roles in shuttling knowledge about the cap-and-trade policy, which was shown to be successful in the US for local officials from the environmental bureau [13].

\subsection{Forms of Policy Transfer}

Voluntary transfer, direct coercive or negotiated transfer, and indirect coercive transfer are major forms of policy transfer established in some of the earliest literature on policy transfer $[23,31,34]$. Voluntary transfer in a country tends to stem from the public's dissatisfaction with the status quo or the lack of effective policies to tackle long-standing policy problems [23]. It is inherently motivated by a government's intention to draw policy lessons from other countries to solve policy problems; hence, this is often an actionoriented approach to transfer that is often accompanied by rational and legitimised political strategies to move policy agenda to the mainstream [34]. The use of benchmarking and yardstick competition among the EU governments as tools to measure themselves on a set of common standards is regarded as a form of voluntary transfer and learning [35]. Direct coercive transfer, a much rarer circumstance compared to voluntary transfer, occurs when a government is forced by another government to adopt certain policies [23]. It resembles a 'negotiated transfer', which occurs when a country is compelled by authoritative parties, such as influential international organisations, global financial institutions, or influential donor countries, to adopt certain policies as requisites to receive other forms of advantages such as grants, loans, and foreign or donor investments [34]. Imposing a set of economic rules on developing countries as requisites for receiving financial assistance from the International Monetary Fund and the strict regulatory standards imposed by World Trade Organisations on its member countries are examples of direct coercive transfer [36]. An indirect coercive transfer is often triggered by externalities and interdependence among countries, forcing countries to either work together or emulate certain policies to solve a common problem that directly affects all parties [23]. At times, indirect coercive transfer occurs when countries are concerned with lagging behind their neighbouring countries [34]. Sometimes, this is also a manifestation of fiscal and resource dependence from the receiving jurisdictions [37]. While the above are four distinct forms of transfer, in some occasions, the transfer occurs and sometimes evolves in a continuum that creates a spectrum ranging from complete voluntary transfer, through semi-voluntary transfer, obligated transfer, and semi-coercive transfer, to absolute coercive transfer [38]. It is argued that complete voluntary transfer and absolute coercive transfer are uncommon, and most transfers are more likely to fall towards the two ends of the spectrum [38] or occur in mixtures with both elements of voluntariness and coerciveness [31].

\subsection{Approaches to and Objects of Policy Transfer}

The policy transfer literature has discussed approaches to policy transfer as processes of policy-oriented learning [34], gradations or degrees [31], or mechanisms [30]. The approaches to policy transfer are described as policy-oriented learning that could happen in the forms of copying (adopting a policy or a programme wholesale without modification), emulation (using policy and programme blueprints from other countries as best practices to inform the construction of policy or programme standards), hybridisation (drawing ideas from and combining elements of several successful policies and programmes to suit the unique cultural context of a country), or inspiration (using policy ideas from other countries as motivations to instil fresh thinking of a policy problem to facilitate 
the construction of a different policy solution) [39]. These approaches are related to the four different degrees to policy transfer-copying (complete transfer of the entire policy), emulation (transferring idea behind a policy or a programme), combination (transferring a mixture or different policies or programmes), and inspiration (using policy ideas in other countries to inspire renewed appraisals towards policy problems) [31]. On the other hand, the policy transfer approach can also be attributed to four different mechanisms-learning, competition, coercion, and mimicry [30]. Derived from lesson-drawing [40], learning is described as a rational decision from governments to adopt policies that have worked to produce effective outcomes in other countries and adapt them to local conditions [30]. While competition is demonstrated by the pressing need for more jurisdictions to adopt similar policies such as investor-friendly policies owing to the growing importance of capital mobility, coercion is the exact opposite in which donor countries or entities often compel recipient countries to institute policy change [30]. A recent study on policy diffusion of armed unmanned aerial vehicles (UAVs) suggested that the compelling need for transfer is the intention of policy adopting jurisdictions and hinges on the competition of exporting jurisdictions to maximise their geopolitical and military influence [41]. Mimicry resembles the concept of 'emulation' [31,34], in that countries adopt what are perceived as successful policies and programmes from other countries in a more normative sense to inform the local implementation norms [30].

Policy goals, structure, and content, policy instruments, institutions, ideology, and ideas, as well as attitudes, concepts, and negative lessons, have been identified as the seven objects of transfer [23]. While ideology and ideas, as well as attitudes and concepts, tend to be transferred using inspiration as an approach, policy goals, structure, and content, policy instruments and institutions tend to be transferred using other approaches such as copying, emulation, mimicry, or hybridisation [23].

\subsection{Facilitators of Policy Transfer}

Effective policy transfer occurs through building a thorough understanding and analysis on how a certain policy or programme has shown to be successful in other jurisdictions before adapting it to the local political and operational contexts, including commissioning reports to study the direct consequences of local adaptation of these policies [38]. This is best illustrated by the transfer of the Working Families Tax Credit, which has shown much success in the US, by the Blair government to the UK context [38].

Ideological similarities between the two countries are major facilitators of policy transfer due to agents' tendency to adopt or transfer lessons from jurisdictions that are politically and institutionally closer and more familiar to them $[6,12,23]$. For instance, the transboundary transfer of environmental policies between the US and Canada is attributed to the value consensus between the two countries. In the same vein, the transfer of similar policies between the US and Sweden resulted in the convergence of safety and health regulations in both countries [23]. The shared interest in the need to tackle a common policy challenge between two jurisdictions using a similar regulatory tool also enables collaborative policy transfer, depicted in the collaborative relations between Australia and Sweden in developing a regulatory compliance tool [6]. Likewise, the transfer could also be facilitated by countries that share a similar cultural and linguistic base. In the transfer of regional policies from the EU to Brazil, the history of migratory flows from the EU to Brazil formed an institutional identification on Brazil's part, which paved the way to the transfer through a series of EU-Brazil policy dialogues [32].

Furthermore, political motivation from the host country demonstrated in the form of coercive transfer is another facilitator for transfer to occur, as illustrated in the case of Turkey in which the political will of transfer was galvanised by a strong political desire to receive EU pre-accession funds by the politicians to establish their political legitimacy [42].

Powerful economic incentives and citizens' demand for policy parity may also induce governments to construct similar policies to match their neighbouring countries, creating spill-over effects [35,37]. 
Diplomacy is another facilitator for transboundary transfer to occur [10,32]. For instance, the transfer of regional policies from the EU to China was driven by trade agreements and the intention to preserve diplomatic ties between them [32]. Likewise, the transfer of delta planning and water management expertise from the Netherlands to Bangladesh is also seen as a diplomatic tool in enabling the Dutch government to strengthen and continue building the long-standing bilateral ties between both countries, in addition to helping the Bangladeshi government to achieve its political aspiration to move the country up the income ladder [10].

Broad involvement of the private sector in the transfer process, coupled with intense collaborations between the private sector and the local government, can also facilitate the success of policy transfer [43]. Broad private sector involvement can give leverage to the government to diversify the ownership structure, especially in terms of financing megaprojects. Moreover, the private sector's involvement can accelerate administrative efficiency and give rise to the adoption of market-based operational principles and standards that are attractive to the private sector in the transfer process [43]. In the case of the SinoSingapore Tianjin Eco-City Project, which saw broad-based policy transfer from Singapore to Tianjin, private sector involvement enabled this transboundary project between two countries to enjoy a variety of private financing sources such as corporate bonds, bank loans, and other private capital that extend far beyond government grants. Additionally, market-based operations facilitate both knowledge and capital transfer from various private entities, thereby buffering the financial pressure faced by the local governments in projects financing [43].

Resources are also another important facilitator of transfer, and it has been shown that better-resourced jurisdictions tend to be more successful in transfer due to their higher policy capacity [35].

\subsection{Barriers to Policy Transfer}

The complexity of the policy and programme poses a major barrier to transfer in that a higher degree of complexity tends to affect policy transferability [23]. This is compounded by the lack of information gathered about how something that has operated successfully in a foreign system can work in the local context [38]. For instance, the lack of details of what some policy best practices convey and the lack of systematic evaluations of the transfer processes can lead to scepticism and distrust among the designated officials to implement the transfer [44].

Political influence also plays a part in limiting the amount, degree and extent of policy transfer. This is most commonly observed in selective transfer, whereby individuals or countries look for ideas in familiar places or lessons that would be perceived to receive the least amount of resistance from the electorate. This often narrows the boundary of the search for good lessons and could potentially stifle innovation and constrain the transfer process [38].

Lack of policy capacity is identified as another barrier to successful policy transfer [42]. Most notably, the lack of analytical capacity and the lack of domestic expertise from the host country to facilitate the transfer process often weaken domestic political support for transfer to occur [42].

Institutional and structural constraints faced by agents who are involved in the transfer of policy represent another major barrier to transfer [23]. These constraints entail a lack of bureaucratic efficiency in the receiving country, lack of technological capacity to maintain operational standards in adopting new technology, and lack of economic resources to engage in policy transfer [23]. At times, the difficulty of transboundary transfer could stem from domestic political constraints in securing financial resources and deploying a sufficient number of bureaucrats for transnational activities due to their preoccupation with their existing duties [12]. High leadership turnover without ensuring proper succession in steering the implementation of a newly established programme can also contribute to policy and programme failure [45]. 


\section{Methods}

An in-depth single-case study describing and explaining the formation and evolution of the ASEAN Smart Cities Network (ASCN) was conducted. A case study is a flexible method that can facilitate inquiry revolving around examining a contextualised contemporary phenomenon within its real-life context [46]. From an in-depth study of a single case, inferences can be made to understand a broader context of a similar phenomenon [47]. In documenting and analysing the case, we focused on the early policy process-notably agenda-setting and formulation-of ASCN. As ASCN was formally started in November 2017, focusing on the early policy process would inform its subsequent implementation, in addition to shedding light on how similar policy initiatives could be managed in the future.

Data were collected using a combination of interviews and document analysis [48]. Indepth individual interviews were conducted by the first and the third authors from fall 2019 to winter 2020 with 19 key informants across seven countries, namely, Singapore, Malaysia, Thailand, Indonesia, Vietnam, Laos, and Myanmar. The respondents were mainly mid-level and high-level civil servants helming the positions as smart city officers, national-level policymakers, practitioners from the private industries, researchers from universities, and think-tanks comprising sectors such as urban planning, education, national development, and communications. For the 11 respondents who were based in Singapore, either on-site interviews or phone interviews were conducted. The other eight respondents who were based in other ASEAN countries were approached via email for online interviews. A purposive sampling approach was adopted through email invitations sent to all smart city officers from the ASCN. After the first wave of interviews, the snowball sampling approach was adopted through referrals and recommendations to recruit more respondents, particularly in sectors and under-represented areas from the first waves. Semi-structured interviews were conducted to obtain information concerning the formation of ASCN, agenda-setting and formulation of ASCN, scopes of the transfer involved among the network cities in ASCN, significance and rationale of ASCN, agents involved in the transfer processes, and facilitators that propel transfer and barriers to the success of ASCN. In addition to interviews, document analysis was conducted through secondary information collected from news articles, official websites of ASCN and the ASEAN Secretariat, policy documents, and government reports.

Both interview data and secondary information from official documents were triangulated to achieve credibility and reliability of the information obtained [49]. These data were analysed thematically to identify similar themes, and the case narratives were strengthened by pattern matching and explanation building to derive logical explanations to the events and insights unfold [46,50]. In analysing the data, we focused on teasing out the early policy processes of the ASCN, mapping out the major actors involved, and determining the role of Singapore in the ASCN and the responses from other ASEAN members, the scopes of knowledge exchange or transfer within the ASCN, and enablers and barriers to the ASCN.

\section{Findings}

\subsection{The Formation of the ASEAN Smart Cities Network (ASCN)}

The idea of ASCN was first proposed by Singapore's Prime Minister Mr Lee Hsien Loong at the ASEAN leaders' summit in Singapore in November 2017. Within a month of the establishment of the ASEAN Smart Cities Governance Workshop, 26 cities within ASEAN came together to form the network [51]. ASCN aims to serve as a regional platform to create synergistic and multiplier effects for each country in ASEAN and enable them to share best practices and secure funding from private investment and multilateral funding institutions to advance the development of their smart cities [52]. ASCN's role in spearheading smart cities in ASEAN is seen to be significant to its member countries, particularly as the region is expanding with a projected addition of 90 million to the population living in urban cities in the region by 2030. The combined GDP of ASEAN is expected to increase by twofold over the next decade, with the expectation to add one trillion USD 
of GDP in the implementation of technology and digital agenda by 2030 [51]. These rapid demographic and economic expansions introduce significant demands on urban cities, making ASEAN a fertile ground for foreign direct investment in conventional goods and services, as well as technological and digital transformation. These trends are already demonstrated through recent inflows of foreign investments into ASCN from Australia and Switzerland. The Australian government has pledged 30.3 million AUD into ASEAN smart cities, while the Swiss government and the World Bank have jointly established an 18 million CHF Indonesia Sustainable Urbanisation Multi-Donor Trust Fund to facilitate the urban development in Indonesia [52].

As the leader of ASCN, Singapore hosted the first ASCN meeting and workshops in 2018 before passing the baton to Thailand in 2019, who hosted the next annual ASCN meeting on 23 August 2019 in Bangkok [53]. The meeting was also held in parallel with the ASCN Conference and exhibition, where the ASCN's role as a catalyst for economic development was reiterated by Thailand's Minister of Foreign affairs. Other important outcomes from this meeting also included the participating countries selecting Singapore to provide advice and support as an 'ASCN Shepherd' for an additional 2 years. In 2020, the ASCN conference (held online due to the Covid-19 pandemic) was organised by Vietnam as the next ASEAN chair. Keeping the post-pandemic future in mind, the targets for ASCN were extended to include strategies and partnerships between participating smart cities for a post-pandemic economic landscape [54]. Currently, Brunei Darussalam has undertaken the chairmanship for the ASEAN region and will continue the ASCN frameworks in 2021 [55].

\subsection{Analysis of ASCN}

\subsubsection{Major Actors in ASCN}

At its formation in 2018, the Singapore government was key in spearheading the ASCN. The Ministry of Finance (MFA) led the strategic directions of ASCN, with government think-tanks such as the Centre for Liveable Cities (CLC) acting as a knowledge partner. Other core government or statutory boards that were involved in ASCN from Singapore included the Ministry of Trade and Industries (MTI), Enterprise SG, Info-communications Media Development Authority (IMDA), and Smart Nation and Digital Government Office (SNDGO) under the Prime Minister's Office. Beyond government actors, four important groups of stakeholders were also involved in forming and propagating the ASCN agendas. These stakeholders comprised (i) international/regional organisations such as the ASEAN Secretariat that supports the ASCN through its Integration and Monitoring Directorate, (ii) private companies and government-linked corporations (GLCs), (iii) multilateral institutions, and (iv) universities and think-tanks (Respondent 2).

In addition to Singapore-based government and private actors in the early years of ASCN, foreign actors such as the US, Japanese, and Korean companies, as well as the Australian government, also signalled their interests to engage ASCN as a coordinating platform to directly engage and collaborate with all the ASEAN members.

\subsubsection{How Does Singapore Facilitate Knowledge Exchange in ASCN?}

As the network initiator, Singapore facilitated the formation of various partnerships among the cities in the network and various public and private actors both in Singapore and abroad (Respondent 11). Since the inception of ASCN in 2018, there have been more than 40 partnerships forged between member cities and various public and private agencies in Singapore in the form of a memorandum of understandings and letter of intent (Respondent 2).

In addition to facilitating business partnerships and working relations, Singapore has branded itself as a resource provider in ASCN. Various capacity-building efforts were visible in Singapore's engagement with the member cities. Government-led think tanks such as the Centre for Liveable Cities (CLC) and the Ministry of Foreign Affairs (MFA) have been organising various capacity-building workshops several times a year, and delegates 
from each member cities, typically comprising a political office holder, a technocrat, and a junior bureaucrat, have been invited. These workshops create a sharing platform for Singapore to share its urban planning and management history and experience from the policy perspective. Based on each workshop's feedback, the agendas were developed to serve the learning needs of the member cities. For instance, one of the major limitations highlighted by member cities is the lack of expertise and experience in procurement and funding solicitation. As a result, a workshop in 2019 was organised to transfer knowledge in writing bankable proposals to improve cities' capacities in soliciting funding. The MFA usually sent out such official invitations and announcements. Aside from public agencies and the private sector, retired senior government officials were also mobilised as consultants and advisors to ASCN through the facilitation of CLC. Their advisory roles serve to enhance the legitimacy of ASCN, as well as potentially offer smart city ideas and solutions to ASCN (Respondents 2 and 12).

\subsubsection{Significance of ASCN to Singapore and ASEAN}

The formation of ASCN is largely seen as a soft power extension for Singapore, in line with its intention to be a responsive global city to share its success stories and urban management lessons with other aspiring cities in the region (Respondent 2). ASCN is a natural step forward in Singapore's diplomatic move to engage its ASEAN partners, as well as to be more connected in the region, which would likely bring more opportunities for the youth to diversify their exposures and skillsets in the face of the Fourth Industrial Revolution (Respondent 8). Furthermore, most ASEAN members perceive Singapore's unique position as an acclaimed world-class city and a leading global business and technology hub that could provide the leadership and technical expertise in institutionalising smart city solutions (Respondents 3-6, 9, 16, and 17). Having gained experiences from decades of rapid domestic social development and having benefited from various technology transfers from other advanced economies in the past, Singapore's public and private sectors are well positioned to expand their footholds and export their urban management experiences to a wider ASEAN region (Respondent 16). Many mega-cities and second-tier cities in ASEAN have witnessed massive urbanisation and exponential population growth but are yet to close the gaps of infrastructure provisions as the demands for basic public services rise. Through ASCN, better collaborations among major cities in ASCN can be established to fill these infrastructure gaps (Respondents 12, 14, and 16). Additionally, ASCN can spur healthy geopolitical competition among the member cities in the network and enable cities to offer smart city solutions to one another. Instead of marketing Singapore as the only solution exporter, ASCN should be branded as a platform that allows cities to forge collaborations to offer solutions that could address similar developmental needs (Respondent 12).

ASCN is seen as a symbiotic platform for private companies and start-ups to work directly with the governments across major cities in the region. It is the first initiative in ASEAN that links city to city directly, which could potentially minimise bureaucracy and enable smart city policies and solutions to be implemented more easily (Respondent 9). While this diaspora enables companies to reach out to a larger market and boost their business opportunities, it also allows governments to tap into some of the smart city solutions that these companies are providing (Respondent 5). There is also strong interest from the private companies based in Singapore for a more visible and institutionalised platform that provides stability and continuity, and ASCN is perceived to hold this promise. As many smart city solution providers are not equipped with the know-how to navigate the complexity of politics and bureaucracy in other ASEAN countries, a Singapore-initiated platform like ASCN provides a well-coordinated structure and integrating buffer for the private actors (Respondent 9).

Furthermore, the formation of ASCN can further strengthen ASEAN as a brand name and regional pact that is competitive and strong among all the strategic alliances in the world. Better regional cooperation established through ASCN will also enable all ASEAN 
countries to cast away the shadows imposed by some of the largest economies in the world, such as the US and China, by balancing their political hegemonies, in addition to leveraging Singapore's good relations with these major superpowers (Respondent 10). In a fast-changing world imbued with higher uncertainties today, smart city development is not just a grandiose aspiration but an imperative for ASEAN (Respondent 9).

\subsubsection{Scopes of Knowledge Exchange and Transfer in ASCN}

In ASCN, the scopes of knowledge exchange and transfer occur multidirectionally. Owing to Singapore's role as the leader of the network, most of the knowledge exchanges flow from Singapore to other ASEAN cities in the network at this point. These cities are ready to learn some of the developmental success stories from Singapore (Respondent 6). Moreover, Singapore's status as a global city also makes it a legitimate initiator for it to expand its effort in sharing the successful policy lessons in smart city development. Its ability to transform from a third-world to a first-world country within three decades is still an inspiration to many. The developmental challenges that it has faced along the way could provide governance lessons and benchmarking systems to other cities (Respondents 3, 6, and 15). In Singapore, CLC is designated to achieve this role, becoming the de facto resource provider in the ASCN platform, linking cities within the network to appropriate resources in Singapore based on their respective urban development problems (Respondent 2). Capacity-building workshops were held quarterly in Singapore in which government delegates from the member cities were invited to Singapore to network and learn from one another, specifically in terms of urban planning and management. These engagements often occurred in formal and informal conversations and exchanges, direct learning through the forging of city-to-city partnerships, training, and sharing of citylevel experiences, and consolidation of best practices across cities (Respondent 6 and 15). In addition to facilitating city-to-city learning, initiatives were started to connect retired government officials in Singapore in the policy process with some cities in the network to provide consultancies at the policy level (Respondent 2). In these capacity-building workshops, other countries / cities can work with Singapore-based companies to develop technology-based solutions to urban problems and to tap into the prowess of technologies in city planning (Respondent 3). Essentially, CLC also aims to create a bigger regional consumer market for local companies eyeing to expand their business ventures beyond Singapore (Respondent 2).

Within ASEAN, the scopes of knowledge exchange and learning are either bidirectional or multidirectional. In addition to Singapore, other countries such as Malaysia and Thailand have emerged as knowledge providers for smart city development to other ASEAN cities (Respondents 3 and 6). Malaysia, for instance, launched its own Smart Cities Framework in 2019 [56]. Furthermore, it was also opined that a big country such as Thailand, with cities of diverse nature, could offer multipronged solutions to other second-tiered and third-tiered cities in ASEAN which are aiming to focus on one industry. For instance, Thailand has cities that are agriculture-based, tourism-based, elderly dominant, and heritage-oriented, in addition to the commercially driven cosmopolitan city of Bangkok. These diverse experiences and lessons in governing cities of a specific nature could be emulated by many other developing countries in ASEAN aspiring to infuse a strong social focus in their respective smart city development (Respondent 3). Furthermore, ASCN is seen as a platform for less developed countries/cities in the network to obtain developmental assistance needed for leapfrogging various developmental stages when adopting technology solutions in the development of smart cities (Respondent 19).

\subsubsection{Enablers of Transboundary Learning and Knowledge Exchange in ASCN}

Five major enablers - effective branding from Singapore, hunger and thirst for knowledge from ASEAN, presence of alternative funding options, enthusiasm from the commercial private actors, and heightened interest shown by external ASEAN members-propel knowledge exchange among member cities within ASCN (see Table 1 for summary). 
Table 1. Enablers of transboundary learning and knowledge exchange in ASCN (source: authors).

\begin{tabular}{c}
\hline Enablers of Transboundary Learning and Knowledge Exchange in ASCN \\
$\bullet$ Effective branding from Singapore \\
$\bullet$ Hunger and thirst for knowledge from ASEAN \\
$\bullet$ Presence of alternative funding options \\
$\bullet$ Enthusiasm from the commercial private actors \\
$\bullet$ Heightened interests shown by external ASEAN members \\
\hline
\end{tabular}

One of the most important enablers of transboundary learning in ASCN is the strong commitment through effective branding of the smart nation idea from Singapore as the leader of ASCN (Respondents 7,10,15, and 16). Singapore is one of the first countries in ASEAN to embark on a Smart Nation Programme (officially launched by the Prime Minister in 2014). Capitalising on the general perception of Singapore as a leader of innovations among the members in the network, Singapore attempts to make a contribution as one of the world's leading global innovation hubs by positioning the smart city idea strategically to its ASEAN partners (Respondent 7). The capacity-building efforts and training opportunities initiated by Singapore and extended to other member cities are also important to sustain the enthusiasm and collective interest towards ASCN (Respondent 10). These efforts are reciprocated by the members, demonstrating clear political commitments from the top leadership level (i.e., mayors, governors) among some of the cities within the network (Respondents 10, 15, and 16).

Another significant enabler of transboundary learning and knowledge exchange in ASCN is the hunger and thirst of cities within the network to learn from one another to bring smart city solutions to their respective cities (Respondents 4, 6, and 17). Through close collaborations and willingness to share developmental lessons related to best practices and technology adoption, member cities within ASCN can foster mutual learning and tap into the collective wisdom of the network to address some of the problems encountered (Respondent 6).

Moreover, alternative funding sources can be an enabler to facilitate the transfer of policy lessons within ASCN (Respondents 16 and 17). For instance, local banks and multilateral institutions can expand their services to the entire region by providing more financing options for cities within the network, especially for cities that are less resourceendowed (Respondent 16).

Enthusiasm for new opportunities from private solution providers to expand their operations beyond a country is another instrumental enabler in facilitating transboundary learning and knowledge exchange in ASCN (Respondent 16). Grassroot involvement and public participation from the local actors are important to see through the development of smart city initiatives in their respective cities and sustain the implementation of these projects or initiatives (Respondent 10).

Heightened interest from the world's major economies towards the investment opportunities in ASEAN through ASCN is another enabler of knowledge exchange among the member cities and the external parties (Respondent 4). For instance, a high-level meeting initiated by Japan Smart Cities Network, held in Yokohama, Japan, in October 2019, enabled member cities to come together to share their respective developmental lessons in the pursuit of their respective smart city agendas, in addition to collectively improving the ASCN smart city action plans [57].

\subsubsection{Barriers to Transboundary Learning and Knowledge Exchange in ASCN}

We also identify five major barriers for enabling transboundary learning and knowledge exchange in ASCN-lack of strong political will among ASEAN countries, entrenched multilevel bureaucracy and complex governance structures impeding communication and reporting, lack of resources (fiscal), lack of sufficient policy capacity, and lack of operational and regulatory mechanisms (see Table 2 for summary). 
Table 2. Barriers to transboundary learning and knowledge exchange in ASCN (source: authors).

\begin{tabular}{c}
\hline Barriers to Transboundary Learning and Knowledge Exchange in ASCN \\
$\bullet$ Lack of strong political will among ASEAN countries \\
- Entrenched multi-level bureaucracy and complex governance structures impeding \\
communication and reporting \\
$\bullet$ Lack of resources (fiscal) \\
- Lack of sufficient policy capacity \\
- Lack of operational and regulatory mechanisms
\end{tabular}

Lack of strong political will among ASEAN countries is one of the major barriers to transboundary learning and knowledge exchange in ASCN (Respondents 1-3, 5, and 6). First, getting political buy-in and ensuring all relevant stakeholders agree to the visions of smart city development and subsequently taking ownership in realising and sustaining these visions often present governance challenges in smart city development (Respondent 3). Due to limited funding and novelty of the smart city ideas, smart city adoption is slow in many ASEAN countries. This is compounded by the long-haul process taken in the political engagement process for technocrats to convince decision-makers to pursue certain smart city ideas (Respondent 6).

Furthermore, entrenched multilevel bureaucracy and complex governance structures in some countries impede the communication process needed to pursue seamless development in knowledge transfer and learning (Respondents 2, 4, 5, 8, and 9). Some respondents opined that, in large countries, facilitating multi-agency collaboration is a huge challenge, creating many 'reporting entities' that slow down the execution process to drive common programmes that could benefit all cities collectively (Respondents 4 and 5). Unlike Singapore's Smart Nations Office, which reports directly to the Prime's Minister Office, many other city-level smart city offices are subsumed under the local government office at the municipal or provincial levels. Often, they do not enjoy similar mandates as the Singapore Smart Nations Office that can drive many smart city initiatives directly and effectively (Respondent 4). The lack of a clear reporting mechanism and the multilevel governance structure impede effective cross-jurisdictional learning. Across ASEAN, there is a lack of a policy champion at the national level that could also navigate local-level bureaucracies to exert pressure for the adoption of ideas required for smart city development at the city level (Respondent 9).

Lack of resources is also a common problem that hinders transboundary exchange and learning (Respondents 1-3, 6, and 15). Many countries in ASEAN are struggling with having sufficient fiscal resources to finance smart city projects. It is commonplace that letters of intent and Memoranda of Understanding (MOUs) may not lead to concrete projects due to ambiguity in the nature of funding with the partners (Respondents 11 and 12). In some ASEAN countries with large populations, strategic decisions often have to be made to prioritise cities that will see immediate impacts from smart city developments in the face of scarce resources (Respondent 3). Priorities of each city and country may also change in the face of institutional or political reforms (Respondent 15).

Lack of sufficient policy capacity that could see through the fruition of different smart city projects is perceived as a barrier in promoting transboundary learning and knowledge exchange in ASCN. In many ASEAN countries, the ability to articulate a smart city problem effectively in a coherent proposal that could appeal to donors is lacking. That is to say, the ability to come up with a bankable proposal is lacking due to the deficit in analytical capacity within the bureaucracies (Respondents 2, 11, 12, and 15). High turnover of smart city officers in some ASEAN countries is common, and new Chief Smart City Officers often encounter a steep learning curve to catch up with the developmental trends (Respondent 4). Smart city roadmaps in each city need to be followed through and implemented. To systematise this, there is a need to construct a set of unifying performance indicators that apply to all smart cities in ASCN, which is currently lacking (Respondent 5). Building the right ecosystem that supports smart city development and promotes PPP 
fairly and transparently is also lacking among the member cities of ASCN (Respondent 5). Furthermore, the capacity to steer implementation at both the national and local levels is an issue. To date, there remains a lack of clarity in the current national policy frameworks and existing legal infrastructures that can facilitate smart city initiatives in some countries in ASEAN (Respondents 9 and 16).

The lack of operational and regulatory mechanisms also poses a barrier to effective knowledge transfer in ASCN. To date, there is a lack of official protocols to follow up with the various partnerships and MOUs formed from each ASCN meeting. For instance, CLC has limited knowledge about the extent to which these projects have made progress (Respondent 2). Furthermore, implementation mechanisms to help cities realise their action plans through different funding opportunities is lacking (Respondent 17). Clear project planning, coordination among different parties, a better understanding of the smart city technologies deployed, and long-term planning are operational codes that need to be set in place in time to come (Respondent 16). The lack of regulatory mechanisms for smaller start-ups intending to get a foothold in other countries has also surfaced as a barrier to creating an inclusive knowledge exchange platform, as there is a lack of mechanisms to connect local start-ups in Singapore with other smart cities in the region (Respondent 7).

\section{Discussion}

The case of policy transfer within the ASCN has found that most transfers are voluntary transfers between cities intending to learn from Singapore or between cities that have identified commonalities in the urban challenges faced. Overall, the scope of knowledge transfer is fairly limited to the transference of policy ideas at the initial stage. While the ASCN is primarily driven by government actors and government-linked corporations in Singapore at this point, involvement across the private sector, including conglomerates, start-ups, small and medium enterprises, and other commercial entities, should be promoted in the longer run. Furthermore, academics and researchers should also be proactively engaged with the industries to codesign smart city solutions. A multipronged and multi-stakeholder approach should be considered to include citizens in the framework of smart city development, whereby they could be mobilised to be more actively engaged in various smart city initiatives, especially at the stage of idea conceptualisation.

On the above note, ASCN could potentially draw inspirations from many other emerging academic or civil society-driven smart city observatories or councils that have been launched across the world recently. For instance, the Smart Cities Research Cluster at the University of New South Wales in Australia directly engages citizens through participatory urbanism, as well as industrial experts, to develop sustainable smart infrastructures and smart service delivery through the use of smart technologies and evidence-based design [56]. Likewise, the Australian Urban Observatory, a non-profit platform started by RMIT university with a more domestic focus, aims to transform complex urban data into easily understood liveability maps across entire Australian cities to facilitate policy decision making [58]. In Europe, Smart City Labs have been established at the city level and regional level to connect industry experts, scientists, and citizens to experiment with new ideas, prototypes, and services in various areas ranging from transport to logistics and healthcare [59,60]. For example, the United Smart Cities Lab in Vienna has been designed as an open workspace for companies and start-ups to have easy and direct access to city representatives, technology providers, and international experts to utilize platforms and solutions, as well as meet early adopters willing to bring their ideas to life [60].

Our findings also shed light on the importance of considering local contexts when the transfer happens $[11,61,62]$. The transfer is a continuous process, and it is important to consider how the entire idea will come together wholly over time [11]. Learning is often an open and unstructured process that involves lesson-drawing and borrowing ideas rather than a wholesale translation of concrete policy content [12]. Even with the member states in European Union (EU), it has been acknowledged that substantial differences in social, cultural, institutional, and economic situations among the member states often 
reduce the relevance and applicability of best practices identified. For instance, policy options for urban spatial planning should be differentiated to suit national contexts, and, instead of adopting the identified best practices, it is better to take them as references and adapt them to local circumstances [44]. As such, contextualising the bureaucratic hurdles and bureaucratic culture in each country is important. Moreover, politics, administrative culture, and policy capacity are different across different cities in the network, and all these contextual factors should be considered. Furthermore, the strategic alliances that ASEAN members forge with world superpowers such as the US, China, and the EU need to be considered in the context of ASCN. These relations need to be understood holistically to avoid contradictions and diplomatic tensions.

\subsection{Trans-Boundary Learning: Policy Implications for Singapore and ASEAN}

5.1.1. Promoting Enablers of Knowledge Transfer and Drivers of Smart City Development for Cities in the ASCN

The five enablers identified in this case study should be strengthened to sustain the interests from the cities within the network to engage in long-term partnerships and initiatives in the future. Furthermore, these enablers can be promoted in tandem with other major drivers of smart city development in developing countries identified by a prior review study [63]. These include building the financing capacity of the city government, building a strong regulatory environment that fosters investor confidence and citizen trust, building up technology and infrastructure readiness, investing in human capital through upskilling and skill enhancement, ensuring stability in economic development, active citizen engagement in determining smart city solutions, welcoming knowledge transfer and participation from the private sector, and creating a supportive ecosystem that promotes innovation and learning [63]. Indeed, these factors, coupled with a governance style that is highly adaptable to the emerging needs required to foster fertile grounds for various technology test-beds, as well as a favourable regulatory milieu for the implementation of novel technology, are essential ingredients identified in Singapore's success in rolling out novel and disruptive technologies [64-66]. As such, Singapore is well positioned to be the conduit to facilitate knowledge exchange and policy transfer for smart city development. As a regional pact, ASEAN should embrace cross-regional and cross-continent partnerships that could elevate the collaborations formed within the ASCN. While the US, Japan, Korea, and Australia have signalled strong interests to engage the network cities, ASCN could consider tapping into the economic prowess of other advanced OECD countries to galvanise global collaboration around innovation [52].

\subsubsection{Addressing Policy Challenges by Building Local Policy Capacity}

Defined as 'the ability to marshal the necessary resources to make intelligent collective choices about and set strategic directions for the allocation of scarce resources to public ends' [67], policy capacity encompasses three major competencies/skills required, operational, analytical, and political, as well as capabilities/resources at three different levels, individual, organisational, and systematic [68]. In many cities within the network, the capacity to turn policy ideas into long-term concrete implementation plans has been identified as a challenge. This is compounded by the fact that countries with vast geography tend to observe enormous disparities in local policy capacity [69]. To ensure a successful transfer, long-term capacity-building efforts within ASCN, which are instituted as the focus of each partnership forged in different smart city ventures, should focus beyond the expansion of governmental bureaucratic capacity at the system level. Within cities, initiatives need to be planned to galvanise capacity-building efforts at the organisational and individual levels. To do so, the three core domains of policy capacity should be given emphasis. While operational and analytical capacities can be developed incrementally through workshops and long-term mentorship programmes, political capacity necessitates strong political will from the local government, as well as acknowledgement of the importance of smart city solutions in tackling some of the most pressing urban problems. 


\subsubsection{Collaborative Policy Transfer between a Transfer City and a Recipient City}

At the point of writing this article, the complete implementation and execution of smart city ideas remains to be observed in the network, and concrete collaborations are yet to be formed (Respondent 4). Due to its nascent formation, ASCN currently lacks a success story, and the long-term return of investment is unclear (Respondent 12). Policy transfer is an iterative process of learning, adjustment, and improvement which will only be effective when subjected to jurisdictions' domestic processes of analysis, evaluation and review [6]. Adopting the spirit of collaborative policy transfer is important to mobilise resources and interests from two or more jurisdictions facing similar policy concerns to collectively enhance critical thinking and reflexive practices towards finding solutions for the problems faced [6]. Hence, stronger partnerships can be identified between a transfer city and a recipient city within the network, whereby a common policy problem regarding smart city development that is inflicting both cities is mutually identified. A transfer city would possess a stronger capacity to tackle the same problem, but it remains relatable to the recipient city in terms of its developmental stage, political culture, and social mores. The recipient city could draw lessons from the transfer city in different stages of the policy process, particularly in implementing and evaluating a specific smart city solution.

\subsubsection{From an Information-Sharing Platform to Tool- or Instrument-Based Transfer}

The ASCN should also look beyond being an information-sharing platform and explore ways to bring about tangible benefits to the member cities within the network (Respondents 3 and 4). As such, policy transfer between cities in the future ought to pay more attention to the details of transfer beyond ideology transfer. For instance, in urban planning, documenting examinations of the transferability of spatial planning methods, tools, techniques, and operating rules would be worthwhile instead of transferring policy ideas without considering the different jurisdictional contexts [44]. Moving forward, policy transfer within the ASCN could consider tool- or instrument-based transfer that directly addresses a niche urban problem using technological solutions.

\section{Conclusions}

As a new and exclusive regional smart city network in Southeast Asia, ASCN is important for Singapore and ASEAN to strengthen their geopolitical positions. It links the governments of Singapore and major cities in the region and creates cross-border business opportunities for private companies and start-ups. This study examined the agenda-setting and formulation processes of ASCN on the grounds of an in-depth analysis based on primary data collected through 19 key informant interviews and secondary data collected through a desktop search. This study delivers a comprehensive investigation of scopes, enablers, and barriers of transboundary learning and transfer in ASCN.

This study demonstrates that ASCN is promising to serve as a regional platform for cities across ASEAN countries to forge collaborations with one another in smart city development and enable knowledge sharing of best practices. ASCN has seen policy transfers from Singapore to cities intending to learn from Singapore or between cities that face common urban challenges. Singapore has effectively branded the smart nation idea and offered to be a resource provider in ASCN. Assuming this role enables Singapore to facilitate knowledge exchanges among cities in ASEAN, bolstered by other facilitators, including a thirst for knowledge from other ASEAN member countries, access to alternative funding resources, enthusiasm from private sector actors, and heightened investment interests from the major economies of the world.

However, ASCN is at an initial development stage, and there is room for improvement. First, policy transfers across national borders in ASCN are mostly focused on exchanges of policy ideas. ASCN should move forward transboundary learning beyond ideology transfer, paying attention to exchanges of policy instruments and institutions with considerations of local contextual details. Given that there are few cases of complete implementation of smart city ideas, emphasising tool- or instrument-based transfer and 
calibrating these tools or instruments over time is conducive to concretising smart city ideas and plans [70]. Rather than transferring policy ideas, the tool- or instrument-based transfer also brings up the importance of contextualising the policy instruments being transferred, especially in a culturally diverse region like ASEAN. Second, there are spaces for member cities in ASCN to pursue further cooperation so that collaborative policy transfers can be established. Considering that policy learning is an iterative process, collaborative policy transfer can mobilise resources (e.g., financial resources, policy capacity) and similar interests from both a transfer city and a recipient city to collectively find solutions for the common policy challenges faced. Third, ASCN is primarily driven by government actors and government-linked corporations in Singapore at the moment, but it is critical to have a broader involvement of the private sector, academics and researchers, and citizens. Active involvement of citizens and private sector actors have been identified as enablers of policy transfer in the literature, while academics and researchers, private sector actors, and bureaucrats and technocrats are the three key groups of agents for transboundary policy transfer.

This study offers crucial policy implications for transboundary learning and transfer in ASCN. Our findings also shed light on the transition from ideology policy transfer to instrument-based policy transfer and the importance of incorporating local contexts when the transfer happens. Empirically, this study contributes to the literature on smart cities by addressing the knowledge gap-the relative lack of understanding of how policy transfer occurs in the context of smart city development and how transboundary learning occurs in a regional network like ASEAN that presents diversity in developmental stages, cultural norms, and economic interests for each country.

Author Contributions: Conceptualisation, A.T.; methodology, S.-Y.T. and A.T.; validation, A.T.; formal analysis, S.-Y.T. and A.T.; investigation, S.-Y.T. and A.T.; resources, A.T.; data curation, S.-Y.T. and K.S.; writing and editing S.-Y.T., A.T. and K.S.; supervision, A.T.; project administration, A.T.; funding acquisition, A.T. All authors read and agreed to the published version of the manuscript.

Funding: This research is supported by the National Research Foundation, Prime Minister's Office, Singapore under its Campus for Research Excellence and Technological Enterprise (CREATE) programme and the Lee Kuan Yew School of Public Policy, National University of Singapore.

Institutional Review Board Statement: Not applicable.

Informed Consent Statement: Not applicable.

Acknowledgments: Araz Taeihagh is grateful for the support provided by the National Research Foundation, Prime Minister's Office, Singapore under its Campus for Research Excellence and Technological Enterprise (CREATE) programme and the Lee Kuan Yew School of Public Policy, National University of Singapore.

Conflicts of Interest: The authors declare no conflict of interest.

\section{References}

1. Hulme, R. The role of policy transfer in assessing the impact of American ideas on British social policy. Glob. Soc. Policy Interdiscip. J. Public Policy Soc. Dev. 2006, 6, 173-195. [CrossRef]

2. Greener, I. Understanding NHS reform: The policy-transfer, social learning, and path-dependency perspectives. Governance 2002, 15, 161-183. [CrossRef]

3. Marsden, G.; Frick, K.; May, A.; Deakin, E. How do cities approach policy innovation and policy learning? A study of 30 policies in Northern Europe and North America. Transp. Policy 2011, 18, 501-512. [CrossRef]

4. Dussauge-Laguna, M.I. Policy Transfer as a "Contested" Process. Int. J. Public Adm. 2013, 36, 686-694. [CrossRef]

5. Müller, P.; Slominski, P. The politics of learning: Developing an emissions trading scheme in Australia. Glob. Environ. Politi. 2017, 17, 51-68. [CrossRef]

6. Walker, C.K. Policy transfer in a corporatist context: Agents, adjustments and continued innovation. Public Policy Adm. 2017, 34, 308-328. [CrossRef]

7. Martin, B.; Geglia, B. Korean tigers in Honduras: Urban economic zones as spatial ideology in international policy transfer networks. Politi. Geogr. 2019, 74, 74. [CrossRef] 
8. Miao, J.T. Parallelism and evolution in transnational policy transfer networks: The case of Sino-Singapore Suzhou Industrial Park (SIP). Reg. Stud. 2018, 52, 1191-1200. [CrossRef]

9. Moodley, S. Defining city-to-city learning in southern Africa: Exploring practitioner sensitivities in the knowledge transfer process. Habitat Int. 2019, 85, 34-40. [CrossRef]

10. Hasan, S.; Evers, J.; Zwarteveen, M. The transfer of Dutch Delta Planning expertise to Bangladesh: A process of policy translation. Environ. Sci. Policy 2020, 104, 161-173. [CrossRef]

11. Yong, L.M.O.; Cameron, A. Learning from elsewhere: Integrated care development in Singapore. Health Policy 2019, 123, 393-402. [CrossRef] [PubMed]

12. Shefer, I. Policy transfer in city-to-city cooperation: Implications for urban climate governance learning. J. Environ. Policy Plan. 2018, 21, 61-75. [CrossRef]

13. Takao, Y. Policy learning and diffusion of Tokyo's metropolitan cap-and-trade: Making a mandatory reduction of total CO2 emissions work at local scales. Policy Stud. 2014, 35, 319-338. [CrossRef]

14. Tanaka, Y.; Chapman, A.; Sakurai, S.; Tezuka, T. Feed-in tariff pricing and social burden in Japan: Evaluating international learning through a policy transfer approach. Soc. Sci. 2017, 6, 127. [CrossRef]

15. Qiao, G.; Oishi, N. Policy transfer from the UN to ASEAN: The case of trafficking in persons. Policy Stud. 2019, 40, 131-149. [CrossRef]

16. Low, S.P.; Liu, J.Y.; Wu, P. Sustainable facilities: Institutional compliance and the Sino-Singapore Tianjin Eco-city Project. Facilities 2009, 27, 368-386. [CrossRef]

17. Caprotti, F.; Springer, C.; Harmer, N. 'Eco' For Whom? Envisioning Eco-urbanism in the Sino-Singapore Tianjin Eco-city, China. Int. J. Urban Reg. Res. 2015, 39, 495-517. [CrossRef]

18. Chien, S.; Zhu, X.; Chen, T. Self-learning through teaching: Singapore's land development policy transfer experience in China. Environ. Plan. C: Gov. Policy 2015, 33, 1639-1656. [CrossRef]

19. Lim, K.F.; Horesh, N. The Singapore Fever in China: Policy Mobility and Mutation. China Q. 2016, 228, 992-1017. [CrossRef]

20. Stone, D. Learning Lessons, Policy Transfer and the International Diffusion of Policy Ideas; No.69; University of Warwick, Centre for the Study of Globalisation and Regionalisation: Coventry, UK, 2001.

21. Stone, D. Transfer and translation of policy. Policy Stud. 2012, 33, 483-499. [CrossRef]

22. Busch, P.-O.; Jörgens, H. The international sources of policy convergence: Explaining the spread of environmental policy innovations. J. Eur. Public Policy 2005, 12, 860-884. [CrossRef]

23. Dolowitz, D.P.; Marsh, D. Who Learns What from Whom: A Review of the Policy Transfer Literature. Politi. Stud. 1996, 44, 343-357. [CrossRef]

24. Rose, R. Lesson-Drawing in Public Policy: A Guide to Learning Across Time and Space; CQ Press: Washington, DC, USA, 1993.

25. Bennett, C.J. Review Article: What Is Policy Convergence and What Causes It? B. J. Pol. Sci. 1991, 21, 215-233. [CrossRef]

26. Stone, D. Transfer agents and global networks in the "transnationalization" of policy. J. Eur. Public Policy 2004, 11, 545-566. [CrossRef]

27. Simmons, B.A.; Elkins, Z. The Globalization of Liberalization: Policy Diffusion in the International Political Economy. Am. Politi. Sci. Rev. 2004, 98, 171-189. [CrossRef]

28. Walker, J.L. The Diffusion of Innovations among the American States. Am. Politi. Sci. Rev. 1969, 63, 880-899. [CrossRef]

29. Shipan, C.R.; Volden, C. The Mechanisms of Policy Diffusion. Am. J. Politi. Sci. 2008, 52, 840-857. [CrossRef]

30. Marsh, D.; Sharman, J. Policy diffusion and policy transfer. Policy Stud. 2009, 30, 269-288. [CrossRef]

31. Dolowitz, D.; Marsh, D. Learning from Abroad: The Role of Policy Transfer in Contemporary Policy-Making. Governance 2000, 13, 5-23. [CrossRef]

32. Dabrowski, M.; Musiałkowska, I.; Polverari, L. EU-China and EU-Brazil policy transfer in regional policy. Reg. Stud. 2018, 52, 1169-1180. [CrossRef]

33. Bok, R.; Coe, N.M. Geographies of policy knowledge: The state and corporate dimensions of contemporary policy mobilities. Cities 2017, 63, 51-57. [CrossRef]

34. Evans, M. Policy transfer in critical perspective. Policy Stud. 2009, 30, 243-268. [CrossRef]

35. Keating, M.; Cairney, P. Introduction: Policy-making, Learning and Devolution. Reg. Fed. Stud. 2012, 22, 239-250. [CrossRef]

36. Marcoux, J.-M.; Gomez, O.C.C.; Létourneau, L. The Inclusion of Nonsafety Criteria within the Regulatory Framework of Agricultural Biotechnology: Exploring Factors that Are Likely to Influence Policy Transfer. Rev. Policy Res. 2013, 30, 657-684. [CrossRef]

37. Keating, M.; Cairney, P.; Hepburn, E. Policy Convergence, Transfer and Learning in the UK under Devolution. Reg. Fed. Stud. 2012, 22, 289-307. [CrossRef]

38. Dolowitz, D.P. A Policy-maker's Guide to Policy Transfer. Politi. Q. 2003, 74, 101-108. [CrossRef]

39. Evans, M.; Davies, J. Understanding Policy Transfer: A Multi-Level, Multi-Disciplinary Perspective. Public Adm. 1999, 77, 361-385. [CrossRef]

40. Rose, R. What is Lesson-Drawing? J. Public Policy 1991, 11, 3-30. [CrossRef]

41. Ceccoli, S.; Crosston, M. Diffusion and policy transfer in armed UAV proliferation: The cases of Italy and Germany. Policy Stud. 2018, 40, 111-130. [CrossRef]

42. Ertugal, E. Learning and policy transfer in regional development policy in Turkey. Reg. Stud. 2018, 52, 1181-1190. [CrossRef] 
43. Zhan, C.; De Jong, M. Financing Sino-Singapore Tianjin Eco-City: What Lessons Can Be Drawn for Other Large-Scale Sustainable City-Projects? Sustainability 2017, 9, 201. [CrossRef]

44. Stead, D. Best Practices and Policy Transfer in Spatial Planning. Plan. Pract. Res. 2012, 27, 103-116. [CrossRef]

45. Ma, L. Site Visits, Policy Learning, and the Diffusion of Policy Innovation: Evidence from Public Bicycle Programs in China. J. Chin. Politi. Sci. 2017, 22, 581-599. [CrossRef]

46. Yin, R.K. Case Study Research and Applications, 6th ed.; SAGE Publications: Thousand Oaks, CA, USA, 2013; Volume 53, ISBN 9781506336169.

47. Gerring, J. What Is a Case Study and What Is It Good for? Am. Politi. Sci. Rev. 2004, 98, 341-354. [CrossRef]

48. Dooley, L.M. Case Study Research and Theory Building. Adv. Dev. Hum. Resour. 2002, 4, 335-354. [CrossRef]

49. Creswell, J.W.; Miller, D.L. Determining Validity in Qualitative Inquiry. Theory Pract. 2000, 39, 124-130. [CrossRef]

50. Bennett, A.; Checkel, J.T. Process Tracing. In Process Tracing: From Metaphor to Analytic Tool; Bennett, A., Checkel, J.T., Eds.; Cambridge University Press: Cambridge, UK, 2014; pp. 3-38. [CrossRef]

51. Balakrishnan, V. ASEAN must be Innovative, Adaptive to Stay Relevant. Business Times, 26 April 2018. Available online: www.businesstimes.com.sg/hub/asean-singapore-2018/asean-must-be-innovative-adaptive-to-stay-relevant. (accessed on 21 April 2021).

52. Cripps, T. South-East Asia is Getting "Smart" with Urbanisation. The Strait Times, 18 May 2018. Available online: www. straitstimes.com/opinion/south-east-asia-is-getting-smart-with-urbanisation (accessed on 21 April 2021).

53. ASCN. ASCN Reviews Work on Smart Cities. Available online: https://asean.org/ascn-reviews-work-on-smart-cities/ (accessed on 21 April 2021).

54. VNA. ASEAN Smart Cities Network Convenes 3rd Conference. Vietnam Plus, 17 July 2020. Available online: https://en. vietnamplus.vn/asean-smart-cities-network-convenes-3rd-conference/178738.vnp. (accessed on 23 April 2021).

55. ASEAN Chair. Available online: https://asean.org/asean/asean-chair/ (accessed on 21 April 2021).

56. Ministry of Housing and Social Development of Malaysia Final Report of Malaysia Smart City Framework. 2018. Available online: www.kpkt.gov.my/resources/index/user_1/GALERI/PDF_PENERBITAN/FRAMEWORK/FRAMEWORK_SMART_ CITY_FINAL_REPORT_190328.pdf (accessed on 23 April 2021).

57. Japan-ASEAN Integration Fund JAIF Promoting of ASEAN Smart City Network (ASCN) by Commencing a High-Level Meeting. Available online: https:/ /jaif.asean.org/project-brief/promotion-of-asean-smart-city-network-ascn-by-commencing-a-highlevel-meeting/ (accessed on 23 April 2021).

58. Australian Urban Observatory about the Australian Urban Observatory. Available online: https://auo.org.au/about/ (accessed on 23 April 2021).

59. Smart City Basel about the Lab. Available online: https://smartcitylabbasel.ch/en/ueber-das-lab/ (accessed on 23 April 2021).

60. UNECE. The First United Smart Cities SMART CITY LAB Opened in Vienna, Supporting Co-Creation of Solutions for Smart Sustainable Cities Worldwide. Available online: https://unece.org/housing-and-land-management/press/first-united-smartcities-smart-city-lab-opened-vienna-supporting (accessed on 23 April 2021).

61. Mattocks, K. "Just Describing is Not Enough": Policy Learning, Transfer, and the Limits of Best Practices. J. Arts Manag. Law, Soc. 2018, 48, 85-97. [CrossRef]

62. Lewis, J.; West, A. "Learning from Others": English proposals for early years education and care reform and policy transfer from France and the Netherlands, 2010-2015. Soc. Policy Adm. 2017, 52, 677-689. [CrossRef]

63. Tan, S.; Taeihagh, A. Smart City Governance in Developing Countries: A Systematic Literature Review. Sustainability 2020, 12, 899. [CrossRef]

64. Li, Y.; Taeihagh, A.; de Jong, M. The Governance of Risks in Ridesharing: A Revelatory Case from Singapore. Energies 2018, 11, 1277. [CrossRef]

65. Tan, S.Y.; Taeihagh, A. Governing the adoption of robotics and autonomous systems in long-term care in Singapore. Policy Soc. 2020, 1-21. [CrossRef]

66. Tan, S.Y.; Taeihagh, A. Adaptive governance of autonomous vehicles: Accelerating the adoption of disruptive technologies in Singapore. Gov. Inf. Q. 2021, 38, 101546. [CrossRef]

67. Painter, M.; Pierre, J. Unpacking Policy Capacity: Issues and Themes. In Challenges to State Policy Capacity; Palgrave Macmillan: London, UK, 2005; pp. 1-18.

68. Wu, X.; Ramesh, M.; Howlett, M. Policy capacity: A conceptual framework for understanding policy competences and capabilities. Policy Soc. 2015, 34, 165-171. [CrossRef]

69. Tan, S.Y. Bureaucratic autonomy and policy capacity in the implementation of capitation payment systems in primary healthcare: Comparative case studies of three districts in Central Java, Indonesia. J. Asian Public Policy 2018, 12, 330-350. [CrossRef]

70. Li, L.; Taeihagh, A. An in-depth analysis of the evolution of the policy mix for the sustainable energy transition in China from 1981 to 2020. Appl. Energy 2020, 263, 114611. [CrossRef] 